\title{
ICMI Column
}

Jean-Luc Dorier (University of Geneva, Switzerland)

In the most recent issue of the ICMI Newsletter (March 2017), a double editorial was published from the new president Jill Adler and the former president Ferdinando Arzarello. With their authorisation, we re-publish this double editorial here today.

\section{From the desk of the ICMI President Jill Adler}

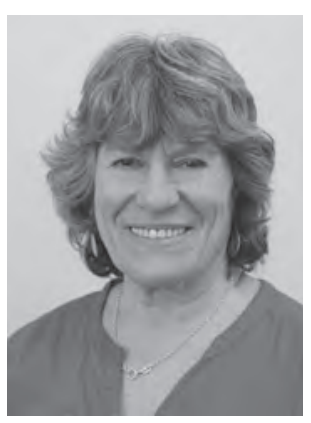

Four years ago, the immediate past president Ferdinando Arzarello wrote from the desk of the ICMI president about the multiple needs mathematics education must serve, where all should have opportunity not only for mathematical literacy but also the adventures of mathematics itself. He drew on the 2012 UNESCO booklet on basic mathematics education written a few years ago mainly by ICMI past president Michele Artigue, assisted by other colleagues in the ICMI. We are pleased to announce this has recently been translated into Portuguese, thanks to the work of ICMI executive committee member at large Yuriko Baldin (http://www. sbm.org.br/?s=desafios+do+ensino). The description of basic mathematics in the booklet highlights the multiple demands on mathematics education and so the need for reform in mathematics in schools, across all levels. In a globalising world, we understand our cultural diversity and the dangers of domination and alienation up ahead for any consideration of common curricula or what is quality teaching and learning of mathematics.

The ICMI launched two studies in response to these challenges. Study 23 on primary mathematics, co-chaired by Maria Bartonini Bussi (Italy) and Xuhua Sun (China), is the first study devoted to early learning and its study volume is almost ready for printing and dissemination. ICMI Study 24, entitled 'School Mathematics Curricu- lum Reforms: Challenges and Changes', has just been launched, with Renuka Vithal (South Africa) and Yoshi Shimizu (Japan) as the two co-chairs. The International Programme Committee has been finalised and will meet later this year to develop the discussion document that will frame its study conference in 2018. This is a strategic moment for the ICMI to collect, analyse, synthesise and then communicate our collective research and practical wisdom in school mathematics curriculum reform. As the new ICMI executive committee prepares for its first meeting in June this year, a key agenda item will be the ongoing support for Study 24, followed by an initial discussion of what might be our next study, and so some considered directions in which to further grow the organisation and its influence.

With these introductory comments, I hope I have illustrated the continuity and growth that now define the organisation, as one executive committee and its new president take over from another. Thus, accompanying this introductory message from the new president is a farewell letter from Ferdinando Arzarello. In this, he describes the developments and progress in the ICMI during his presidency and I take this opportunity, on our collective behalf, to thank Ferdinando and his executive committee for all their work. I will not refer again here to the ongoing continuous work of the ICMI. I will only say that being elected as the president of the ICMI is an immense honour, especially at a time when the organisation is so strong and where a critical component of our strength is our collaborative and increasingly productive relationship with the IMU and the global community of mathematicians.

I will use this opportunity for my first communication with our ICMI community to convey my greetings to you all, each and every participant in all ICMI activities, and to invite you all to participate with me and the new executive committee in ongoing communication about our work - past, present and future. 
In particular, I wish to welcome all national representatives into your roles if you are new this year and to thank those who are continuing in their roles for their ongoing work. We have 94 member countries and each has a representative through whom there is a formal line of communication to and from the executive committee. If you were at ICME13 in Hamburg in July, you would know from Ferdinando's presentation during the opening ceremony that we have numerous member countries and therefore national representatives across some continents but not others. We hope in our term of office over the next few years to enable greater representation and participation from countries in Africa, South and Central America, Eastern Europe and parts of Asia. We are, of course, only too aware of the challenges facing us all with this, as our world seems to have become increasingly unequal and fragmented. You have been introduced to the nine members of the executive committee (http:// www.mathunion.org/icmi/icmi/icmi/executive-committee/ec-2017-2020/) and you can see that we are spread across continents and so hopefully in a good position for this task.

The ICMI executive committee is currently preparing the agenda for our first meeting in June and so, right here, right now, we invite you to communicate with us, with ideas that you would like us to take forward and, of course, concerns with the organisation or its work. Formally, such communication should happen through the national representative in your country. If you are not aware who this is, the list is available at http://www.mathunion.org/icmi/icmi/members/icmi-representatives/.We hope, over the next four years, to strengthen these lines of communication. Of course, you could write directly to me (icmi_president@mathunion.com), to our secretary general Abraham Arcarvi, (Abraham.Arcavi@weizmann.ac.il), to our administrator Lena Koch (icmi.cdc. administrator@mathunion.org) or to any of the executive committee members.

Of course, we have been thinking about our growth. You will all know, and Ferdinando's letter provides detail on this, that a key direction for growth for some time now has been what can be described as a development agenda. Expanding the ICMI's reach into new communities has been a key concern. The Capacity and Networking Project (CANP), and substantial solidarity grants to support participation at the ICME, demonstrate our growing success. In my recent work in South Africa, I have been challenged by how reform ideas in mathematics education are taken up (or not), particularly in developing country contexts, and thus contexts of educational disadvantage. The 2015 millennium goals for universal primary education are becoming a reality. Coupled with this, however, is a concern that while most might now have access to school, in many areas this has not come with quality education. In 2012, the Conference of Commonwealth Education Ministers described this situation as "education for all, learning for some" (www.cedol.org). Just as we confront diversity as we study curriculum reform, so there are different orientations to what is quality mathematics teaching and quality mathematics learning.
I have been stimulated by recent literature and research related to educational development and comparative studies. There has been provocative debate in leading journals (the International Journal of Education Development and COMPARE) on pedagogy promoted in development projects and interventions, particularly in contexts where socio-economic conditions deny quality education to the majority of students in school. The current UNESCO goal is for sustainable development and while this is not specific to mathematics education, it is a programme we in the ICMI can think about, stimulate interest in and contribute to. The goal of sustainable development is shared with the IMU and the CDC (Commission for Developing Countries) and also carried out through its work with the ICSU, the International Council of Scientific Unions. At this moment, we are collaborating with the project Mathematics for Planet Earth, with a new project inviting modules that specifically speak to the African context.

We in the executive committee have also been inspired by the talk entitled Mathematics for Human Flourishing given to the Mathematics Association of America (MAA) by its outgoing president Francis Su in January this year. He framed his eloquent and passionate talk with the question: "How can the deeply human themes that drive us to do mathematics be channelled to build a more beautiful and just world in which all can truly flourish?" He suggests these themes are fun, beauty, truth, justice and love. These are sustainable development goals crafted in a different form for mathematics and so too for mathematics education (https://mathyawp.wordpress. com/2017/01/08/mathematics-for-human-flourishing/).

Being elected as president of the ICMI is thus not only an honour but also a huge responsibility, to ensure the continuing strength of the institution. This is a turbulent period in the world and there are increasing threats to collaboration and social justice and thus flourishing for all. However, as a South African, I have learned over and again how turbulence brings opportunities. During my mandate, and with a wonderful executive committee elected to support the ICMI's work over the next four years, we will work to maximise these opportunities.

Jill Adler, President of the ICMI (ICMI_President at mathunion.org)

\section{Farewell letter from ICMI Past President Ferdinando Arzarello}

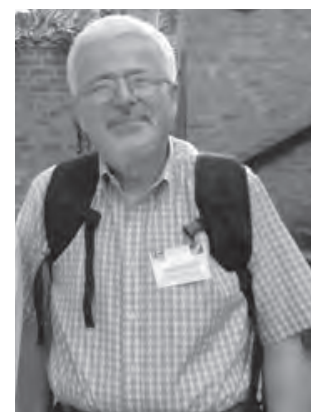

Dear Friends,

At the end of my term as ICMI president, I wish to thank you so much for the strongly collaborative spirit with which we have been able to work together in order to pursue the aims of our joint endeavour. For me, it has been an exciting period: ICMI programmes have allowed me to engage in wonderful chal- 
lenges, whose results I do hope have been useful for supporting and improving mathematics education in many parts of the world.

In this mission, I was strongly sustained by the whole executive committee, whom I thank so much; I am particularly grateful to the secretary general and to the two vice-presidents for their precious advice in many circumstances. In the case of Abraham, the continual interactions have also developed a deep friendship: many times I realised that we were sharing a common interpretation of circumstances even before discussing them. I think that these peculiar interactions have also been useful for ICMI policy.

A special thank you must also go to Lena Koch, whose help, collaboration and suggestions incessantly supported and encouraged me in my day-to-day work as president. I think that the whole ICMI family, not only our executive committee, owes her a lot. Thank you Lena!

Usually, custom dictates that at the end of their term people should carry out an analysis of their activity. I do not wish to break this tradition but I also do not like to bore people with long inventories, so I will limit myself to listing some of the ICMI courses of actions that, as far as I can see, are worthwhile underlining.

I consider first the issues that pertain to the ICMI "by default". I will only sketch some of them since the secretary general has given detailed reports on all such activities on many occasions where all of us have been present (e.g. in his report at the last general assembly or in his speech at the ICME closing ceremony: https://lecture2go. uni-hamburg.de/12go/-/get/v/19779). Because of this, I will limit myself to recalling the huge efforts that many of us have made in ICME events, through our participation in the scientific work of the IPC and the important decisions about support to participants from developing countries, and through the careful choice of the country that will host the next ICME. The competition among three top-level contenders like Australia, China and the USA (Hawaii) for hosting ICME 14 shows the increasing relevance that our organisation has for people working in mathematics education.

Another significant activity has concerned the organisation of the general assembly, where the main items of ICMI policy and institutional life are presented, discussed and approved: the minutes of its Hamburg meeting show the relevant contributions of the ICMI Affiliated Organisations (http://www.mathunion.org/icmi/icmi/ icmi-as-an-organisation/general-assembly/) and the high participation of the country representatives. We have taken care, as far as possible, of the links with them and this systematic task has been fruitful. Also, the wide participation of members of the executive committee in the activities of the ICMI regional conferences and other relevant regional events all over the world shows the vitality of our institution.

Another important issue I am happy to mention here concerns the relationship between the ICMI and the IMU: it has improved greatly in recent years, mainly thanks to the intelligent policy of former presidents in that direction, which has continued in these last few years. I wish to thank the current and past presidents and secretaries of the IMU, Ingrid Daubechies and Martin Grötschel, and Shigefumi Mori and Helge Holden, for their support and help. The collaboration with them in everyday activities, as well as in specific programmes, has been wonderful and productive. Moreover, the support of the IMU secretariat, with its distinguished head Alexander Mielke and excellent team (Sylwia Markwardt, Lena Koch, Anita Orlowsky, Birgit Seeliger, Gerhard Telschow and Ramona Keuchel) has always been a precious concrete help for all our activities.

I will finish my farewell with some more "political" thoughts that I have progressively elaborated during my work in the ICMI, thanks to crucial interactions with the members of the executive committee and with many people of the wider ICMI family.

I think that, while designing our programmes, we have reflected extensively on the meaning of mathematics teaching/learning in the era of globalisation: curricula, teachers, classroom practices and cultural, political and social issues. The world frame in this matter (and not only in this) is full of contradictions, which have constituted a challenge for us and I should think a challenge for all, mathematicians, mathematics educators, policymakers and mathematical education societies alike. As pointed out in an important UNESCO document, on the one hand the universality of technological development and related needs for manpower skills are playing the role of strong historical motivation for reform that should lead to unified standards for mathematics in school. But, on the other hand, for real success in mathematics education it is crucial to avoid both the cultural distance of some proposed curricular reforms from the mathematical culture of the different countries, as well as students' alienation from their cultural environment, which can inhibit them from engaging in learning in a productive way.

Based on the inspiring experiences of previous ICMI executive committees, we have devoted many resources and much energy to some projects that we think are crucial for featuring our own policy; among them I recall the four I like the most:

- CANP activities, and how these have improved through the publication of their volumes at an international level, and a scientific survey of CANPs conducted by Lena Koch (her detailed and informative review will be uploaded to the ICMI website in the near future; in the meantime, a long summary is available at http:// www.mathunion.org/fileadmin/ICMI/files/CANP/PP CANP_ICMI_ICME_CANP_WORKSHOP.pdf).

- The ICMI Study 24 on 'School Mathematics Curriculum Reforms: Challenges and Changes', whose launching document, because of its complexity, required a lot of discussion within the executive committee.

- The new Emma Castelnuovo Award, which underlines the relevance of practices in addition to research in mathematics education (according to the ICMI spirit).

- The Klein project, which aims to bridge the gap between the mathematics traditionally taught in second- 
ary school and its most recent results through vignettes that can inspire teachers in their daily activities.

From these experiences, some particularly significant aspects have emerged as major challenges for mathematics education at the beginning of the new millennium and, as is sometimes the custom of people who finish their term, I dare to leave them as a small legacy.

I think that the main fresh challenges concern:

- The education of younger pupils.

- Teacher training.

- The gender gap in mathematics learning.

- The use of internet technologies n.0 $(n>1)$ for mathematics teaching and learning.

For some of these, the ICMI has already done interesting things but I think the ICMI could do even more. For example, with Study 23, the ICMI has started to extend its concerns to primary education. This study focuses on a segment of students that were traditionally not a core concern. I think this most worthwhile new trend will continue in some way. Moreover, the publication of the Study 22 volume on Task Design certainly constitutes an important tool for researchers and practitioners.

Other challenges at the moment are at the stage of promising beta-projects: e.g. the organisation of a MOOC for researchers and teachers as a resource of high-level lectures given by ICME awardees. Others concern the work of specific IMU commissions (where the ICMI has its representing member), which are carrying out projects where the ICMI can provide a relevant contribution.

A last word on what I call the "sleep of reason", rephrasing the title of a well known F. Goya etching
(Capricho 43: "El sueño de la razón produce monstruos"): 'The ongoing tremendous events in many parts of the world seem produced in fact by monsters that such a sleep generates. I think that we can react against this sleep, trying to realise another meaning of the Spanish word "sueño", or "dream": hence, let us struggle for a "dream of reason". Our contribution to this dream can be pursued by supporting and strengthening the diffusion of a solid mathematical education, rooted in the cultural contexts of the different countries but universal in its final content. It will contribute by helping people think for themselves and understand one another. It will only be a drop in the ocean but not a useless one and it is important that all of us do our best in this.'

This is the legacy I leave to the next ICMI executive committee, which will start its task on 1 January. I wish all its members and particularly Jill Adler (the new president) and Abraham Arcavi (the re-elected secretary general) all my best wishes for continuing and enhancing the ICMI mission over the next four years. As the past president, I will be an ex-officio member of the executive committee and I will have the privilege of continuing to work for the ICMI and collaborate with them in this exciting enterprise.

Dear Friends,

Our common work over these four years has been a really exciting human and cultural experience: apart from our realised programmes, of which all of us are justly proud, our mutual knowledge and friendship is one of the most solid results we achieved. Thank you again!

Torino, 30 Dec 2016

Ferdinando Arzarello, Past President of the ICMI 